\title{
Fragile $X$ full mutations are more similar in siblings than in unrelated patients: further evidence for a familial factor in CGG repeat dynamics
}

Robert W. Burman, BA, Kim S. Anoe, BS, and Bradley W. Popovich, PhD, FACMG

\begin{abstract}
Purpose: We sought to compare patterns of full mutation repeat-length variability in the peripheral blood DNA of patients with fragile $X$ syndrome to determine whether siblings possess mutation patterns more similar than those of unrelated patients. Methods: Mutation patterns were visualized by Southern blot analysis and captured digitally with a phosphor imager. Novel comparison strategies based on overlapping profile plots and calculation of weighted mean CGG repeat values were used to assess mutation pattern similarity. Results: Within the population that we analyzed of 56 patients with full mutation, mutation patterns were found to be more similar in siblings than in unrelated patients. Conclusion: These results indicate that repeat-length variability may be generated in a nonrandom manner and that familial factors influence this process. Genetics in Medicine, 2000:2(4):242-248.
\end{abstract}

Key Words: fragile $X$ syndrome, CGG, repeat-length variability, mutation pattern, familial clustering

Fragile $\mathrm{X}$ syndrome is a common form of X-linked mental retardation caused by expansion of an unstable CGG trinucleotide repeat in the $5^{\prime}$ UTR of the FMRI gene. ${ }^{1-4}$ In normal populations the length of the repeat tract is polymorphic and contains approximately 5 to 50 triplets. These normal alleles are stable both in the somatic cells of an individual and when transmitted between generations. Premutation alleles with approximately 50 to 220 repeats are found in unaffected carriers and, like normal alleles, are usually stable somatically. ${ }^{5}$ However, premutation alleles have a propensity to change size intergenerationally and, when transmitted by a female, can expand to form full mutations with $>220$ repeats. ${ }^{2,5,6}$ Full mutation alleles are almost always associated with hypermethylation of the CGG repeat and a surrounding CpG island. ${ }^{2.7-9}$ Hypermethylation initiates and/or stabilizes transcriptional silencing of the FMRl gene, and the resulting deficit of FMRl protein (FMRP) renders individuals at risk to express the fragile $\mathrm{X}$ syndrome phenotype. ${ }^{10-12}$

Full mutation alleles can be highly unstable in somatic cells. ${ }^{5,13}$ As a result, most patients with full mutations possess a high degree of repeat-length variability, which is manifest on Southern blot analysis as a complex smeared and polybanded mutation pattern. These mutation patterns are typically well conserved among multiple tissues within individuals ${ }^{14-22}$ and can be conserved in monozygous twins. ${ }^{15,23,24}$ Furthermore,

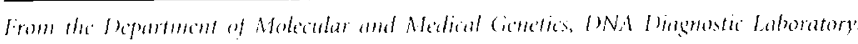

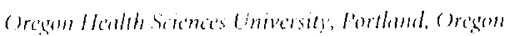

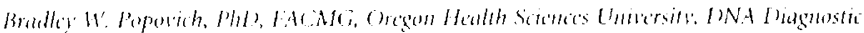

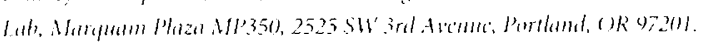

Kicioled: April 12. zonor.

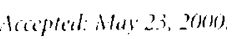

analysis of cultured fibroblasts derived from adult patients with full mutation has demonstrated that methylated full mutation alleles are stable in these cells. ${ }^{17,25}$ Together, this evidence suggests that somatic instability is normally limited to a period during embryogenesis, and thereafter, the repeats are maintained with little or no variation in size. ${ }^{15}$ Somatic mutation patterns might then represent a snapshot of the mutational process frozen at the point the cells cease to be permissive to further changes in repeat number.

Although the process that generates variation of repeat length in somatic cells is likely to involve multiple consecutive changes in repeat number, the instant at which repeat sizes become fixed could reveal a degree of familial similarity if the process is more determinate than stochastic. To our knowledge, analysis of familial similarity in full mutation sibships has not been reported. However, similar mutation patterns have been observed in at least one brother pair with full mutation and was theorized to indicate that other gene(s) may influence the pattern of expansion. ${ }^{26}$ Furthermore, examination of sibships containing only offspring with a premutation has demonstrated familial clustering in which premutation size is significantly more similar within families than between families. ${ }^{27}$ Thus, a so far unidentified familial factor(s) may influence CGG repeat dynamics.

In the present study we assessed mutation pattern similarity in a population of 56 patients with full mutations to test the hypothesis that mutation patterns are more similar within sibships than between unrelated individuals. By examining full mutations, we sought to determine whether a familial factor(s) may influence repeat dynamics in somatic cells. Our data demonstrate that, within the patient population under study, full mutation patterns seem to be more similar within sibships than in unrelated patients. 


\section{MATERIALS AND METHODS}

\section{DNA isolation and analysis}

DNA was extracted from the peripheral blood leukocytes of 56 patients with fragile $\mathrm{X}$ who were referred to the Oregon Health Sciences University DNA Diagnostic Laboratory for diagnostic testing. DNA isolation and Southern blot analysis were performed as described. ${ }^{28}$

\section{Similarity measurements and statistical analysis}

Digital representations of Southern blot membranes were captured with a phosphor-imaging system (PhosphorImager SI; Molecular Dynamics, Sunnyvale, CA) scanning at a resolution of 100 pixels $/ \mathrm{cm}$. The portion of a typical Southern blot that contained relevant data were usually restricted to a region approximately 12 to $15 \mathrm{~cm}$ in length. Thus each lane was composed of 1200 to 1500 rows of data points. Profile plots for each lane in the Southern blot images were generated with ImageQuant software (Molecular Dynamics), and the raw data were exported to Excel version 8.0 (Microsoft, Redmond, WA) for analysis. Because the profile plots are not smooth curves but rather a series of interconnected points, the area under a plot can be estimated simply by summing signal intensity values. For each sample pair used in this study, an Excel spreadsheet was used to calculate total area and area in common, while excluding from analysis that portion of the data that fell below an adjustable baseline. The weighted mean number of CGG repeats in each of the 56 sibling samples also was calculated in Excel as follows: weighted mean lane position $=\Sigma$ ((lane position)( signal intensity)) $/ \Sigma$ (signal intensity). Signal intensity values were obtained with the baseline set at the level of the system background (normal alleles in samples from females were excluded from analysis). Weighted mean lane positions were converted to CGG repeat units by reference to the molecular weight markers (DNA Analysis Marker System; Gibco BRL, Rockville, MD). All statistical analyses, including analysis of variance (ANOVA) and $t$-tests, were performed with SPSS software version 6.1 (SPSS Inc., Chicago, IL). Significance levels are presented without consideration of multiple comparisons.

\section{RESULTS}

To determine whether a familial component influences somatic instability, we studied the genomic DNA of 56 patients with full mutations by Southern blot analysis. The patients were grouped into 16 sibling pairs in 12 families (including 2 families with 3 affected siblings) and 15 pairs of randomly matched unrelated patients. DNA samples derived from peripheral blood were digested with $P$ st I, and each pair was run in adjacent lanes for analysis. PstI was used as the restriction endonuclease, because digestion produces CGG repeat containing fragments that are significantly smaller than those obtained with the more common EcoRI/EagI assay and thus yield much better resolution of the peaks and smears that comprise the mutation pattern. Figure 1 shows representative Southern blot results for seven patients within three sibships that are suggestive of familial mutation pattern similarity.

Numerical descriptions of full mutations are complicated by the often highly heterogeneous mix of allele sizes present within an individual. Consequently, we sought a system in which comparison of mutation patterns could be made directly. One means of representing mutation patterns is the creation of profile plots from phosphor imager-derived Southern blot images (Fig. 2). Using the profile plots, we compared mutation pattern similarity by overlapping two plots and determining the amount of area that the plots shared in common. By measuring similarity as the proportion of the total area that was shared, the data were normalized for gel-to-gel variation in signal strength, allowing integral comparisons to be made. One variable that affects the measurement of area under the profile plots is the selection of the baseline level, below which area is excluded from analysis. When the baseline is set at the level of the system background, the area under the plots is derived entirely from the sample signals, with no contribution from system noise (Fig. 3, panels with "1x baseline level"). To distinguish between specific similarities, such as coincident peaks and less specific similarities that occur near the level of the system background, the baseline was systematically varied by fractional multiples of the system background level (Fig. 3). Using this pattern overlap approach, we obtained similarity measures for each of the full mutation sample pairs at each baseline setting to test the hypothesis that mutation patterns, as measured by shared area, are more similar in the sibling pairs than the unrelated pairs. Comparison of the two groups demonstrated that similarity was not significantly greater in the sibling pairs until the baseline was raised to a level 1.5 times greater than the system background (Table 1). Thereafter, the difference between the sibling and unrelated pairs increased in significance as the level of the baseline was raised.

As an alternative to the profile plot overlap strategy, we used the phosphor imager-derived data to compute the weighted mean number of CGG repeats (wMean-CGG) in each full mutation sample as presented in MATERIAL AND METHODS. In the population of 56 patients with full mutation used in this study, the arithmetic mean of the wMean-CGG values was 575 repeats (range: $318-967$ repeats). We used the wMean-CGG values of the sibling samples to test the hypothesis that variation in the wMean-CGG number is greater between families than within families. Nolin and colleagues ${ }^{27}$ previously used ANOVA to demonstrate highly significant clustering of CGG repeat size in sibships containing only offspring with a premutation. We applied the ANOVA strategy to the 12 full mutation sibships and found that the wMean-CGG repeat sizes were significantly more similar within families than between families $(P=0.004)$. To verify the suitability of the randomly matched unrelated samples as controls in the previous comparison strategy, we applied the ANOVA analysis to the 15 unrelated pairs. As expected, we found no significant difference within and between groups $(P=0.992)$. 


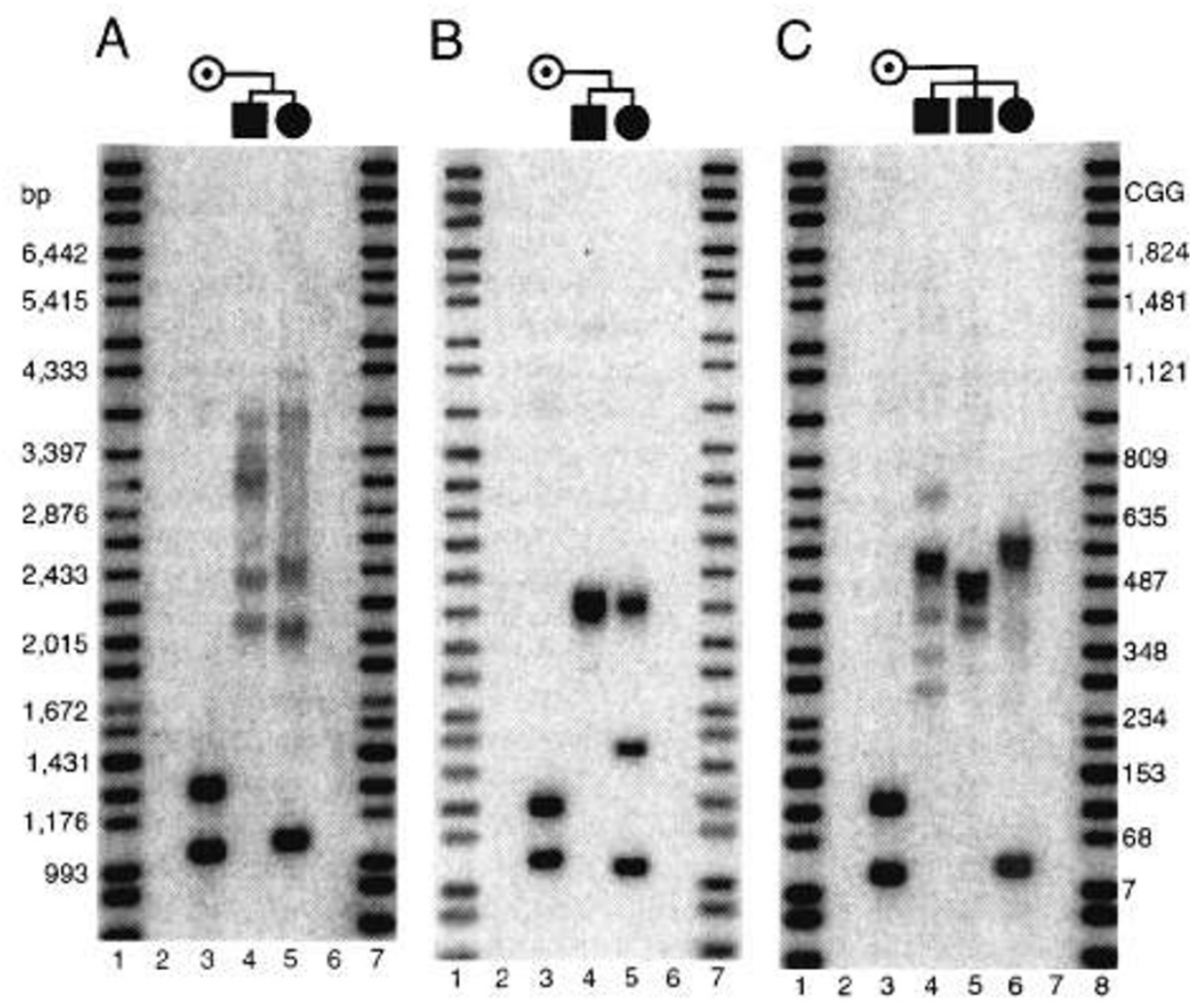

Fig. 1 Repeat-length variability in three fragile X families. (A, B, C) Southern blot analysis of genomic DNA samples digested with PstI and hybridized with probe ffxa3. Each panel contains DNA samples from a premutation carrier and her full mutation offspring. The patterns of repeat-length variability in the sibships show some degree of similarity. In each of the panels, the samples are flanked by blank lanes and the outermost lanes contain a molecular weight marker.

\section{DISCUSSION}

The molecular basis of repeat-length variability in patients with fragile X full mutations is largely unknown. Because the mutational status of the repeat tract in oocytes of premutation females has yet to be described, it is unknown whether the transition from premutation to full mutation occurs prezygotically or postzygotically. Thus, repeat-length variability may be the product of either repeat expansion from an inherited premutation or retraction from an inherited full mutation. Some experimental evidence indicates that full mutations can be tolerated in the oocytes of patients with full mutation ${ }^{29}$ and that premutation alleles in individuals who possess both a full and premutation are better described as retraction events rather than remnants of an inherited premutation that has failed to expand in a subset of cells. ${ }^{20,30}$ Together, this evidence favors a model in which an inherited full mutation undergoes repeat retraction in the cells of the early embryo to produce variation in the length of the repeat tract.

Most models proposed to explain repeat-length variability are based on DNA replication errors involving polymerase slippage $^{31}$ and the formation of secondary structures, such as hairpins, that stabilize slippage structures by minimizing the energy difference between the duplex and slippage states. ${ }^{32,33}$ When CTG repeats are replicated in Escherichia coli, the products of repeat contraction have shown a regularity in size that implies that defined DNA structures may be involved in the contraction process. ${ }^{34}$ Some evidence suggests that defined DNA structures may likewise play a role in CGG repeat variability. In particular, a hotspot for deletions ${ }^{19}$ has been described in a number of unrelated patients with fragile $X$ syndrome ${ }^{19,35-38}$ and in cloned FMR1 sequence replicated in $E$. coli $^{39}$ and Saccharomyces cerevisiae. ${ }^{40}$ One explanation for the existence of this hotspot is that the sequence in the vicinity may be involved in the formation of a secondary structure(s) that mediates the deletion process. ${ }^{19}$ Because many of the deletions in these patients with fragile $\mathrm{X}$ syndrome have unmethylated flanking sequence and occur in mosaic form in conjunction with full mutation alleles, the deletions must be the product of somatic events and may be a consequence of early embryonic repeat contraction extending into flanking sequences before de novo methylation. The identification of similar deletion breakpoints in multiple unrelated patients and other organisms implies that the process may involve conserved DNA structures.

In the current study we applied a strategy of overlapping plots that represent patterns of repeat-length variability to determine whether a familial component may influence the generation of variation in repeat length and whether, by extension, somatic variability may occur in a nonrandom manner, as suggested by the deletion hotspot. One advantage of the profile plot overlap method is that description and comparison of 
A

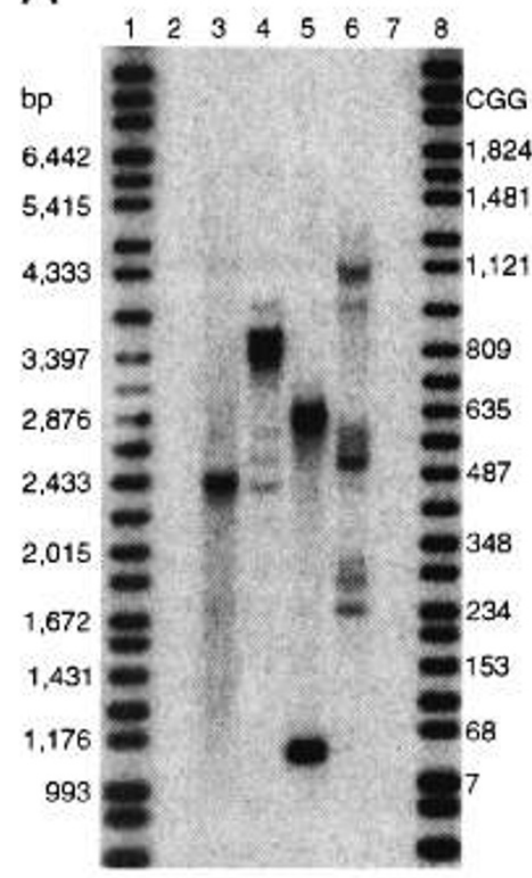

B

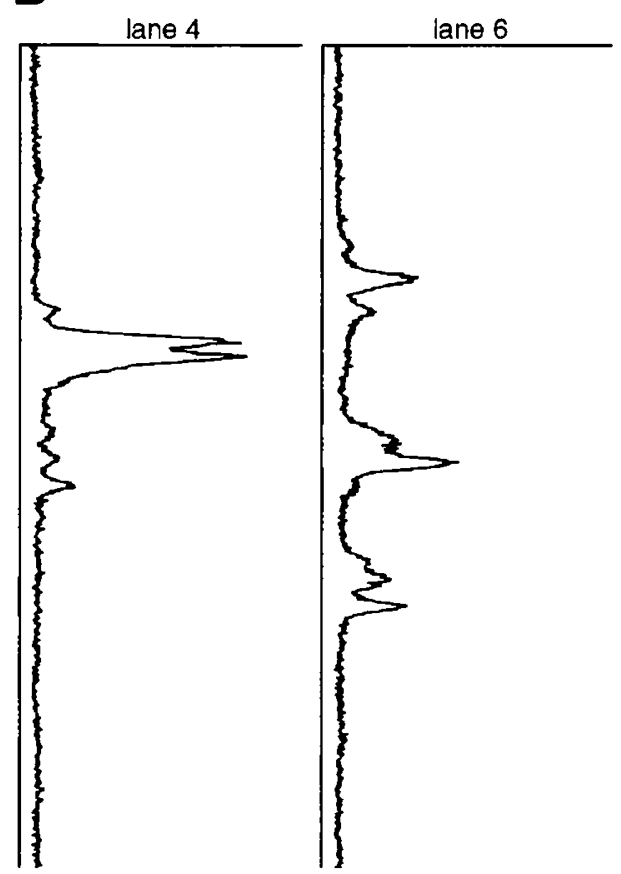

Fig. 2 Profile plot representations of mutation patterns. (A) Southern blot analysis of genomic DNA samples digested with $P_{s t l}$ and hybridized with probe pfxa3. Lanes 3 to 6 are unrelated full mutation samples that were randomly paired before gel loading. The four samples are flanked by blank lanes to avoid signal interference from the molecular weight markers loaded in the outermost lanes. (B) Representative profile plots of the samples in lanes 4 and 6 . Digestion with PstI and long electrophoresis run times allow resolution of mutation pattern features that might not otherwise be visible. Only two of the four possible profile plots are shown in order to conserve space.

patterns can be made directly, with little manipulation of the underlying data. This somewhat mechanical approach has shortcomings as well, including allowing specific similarities, such as two overlapping peaks, to be obscured by less intense but more numerous overlaps that occur as a consequence of most full mutation alleles falling within a common size range. To overcome this weakness, we employed a comparison strategy that uses an adjustable baseline level. Comparison of the sibling pairs and randomly matched unrelated pairs shows that shared area in both groups decreases as the baseline is raised, but in the unrelated group this decrease occurs at a faster rate than in the sibling group. As a result, the difference in mean similarity between the groups grows larger and eventually reaches marginal significance when the baseline is set to a level 1.5 times greater than the system background. Further increases in the baseline result in an increasingly significant difference between the sibling and unrelated pairs. It should be noted that we used a one-tailed $t$-test to assess the a priori hypothesis that similarity is greater in the sibling pairs than in the unrelated pairs. Consequently, the $P$-values we obtained, when considered in conjunction with the relatively small sample size, are of somewhat questionable significance. Nonetheless, the inverse relation between baseline level and $P$-value does indicate a trend in which similarities among the sibling cohort are driven by overlapping peaks, whereas similarities in the unrelated group are the product of low-intensity overlaps that are more readily obscured as the baseline is raised.
In a study addressing familial transmission of the fragile $\mathrm{X}$ repeat, Nolin and colleagues ${ }^{27}$ evaluated familial clustering in sibships containing only offspring with a premutation. In that study ANOVA was used to test for statistical significance and demonstrated that repeat size in the offspring of both male and female carriers was significantly more similar within families than among families. ${ }^{27}$ The analysis of familial clustering in premutation sibships was facilitated by the somatic stability of premutation alleles that results in an absence of length variation and allows a simple numerical description of repeat size. In an effort to describe full mutations numerically in a systematic manner, we used signal intensity to weight repeat size and generate a weighted mean CGG repeat value. These weighted mean values have the advantage that all of the numerous alleles present in a Southern blot representation of a complex mutation pattern contribute to calculation of the weighted mean. In addition, weighted mean estimates are largely free of observer bias, and the simplicity of the description (e.g., one value per full mutation sample) facilitates statistical analysis. When the wMean-CGG repeat values were used in an ANOVA analysis, we found that significantly less variation occurs within families than between families.

Our results suggest that repeat-length variability is generated in a nonrandom process that may be influenced by familial factors. The identity of these factors and the basis of the apparent similarity are not known. One possibility is that repeat variability "pathways" depend on defined DNA secondary 


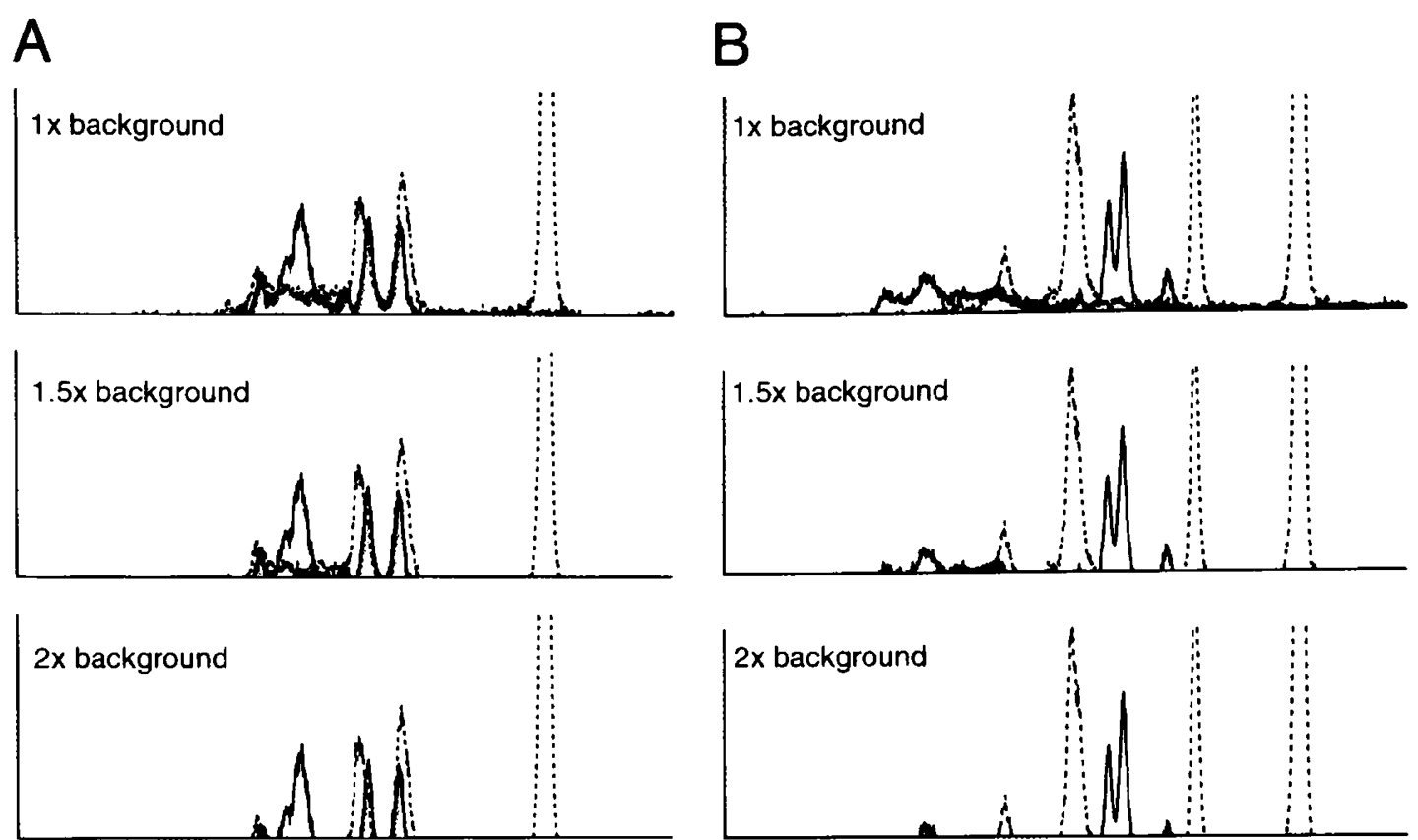

Fig. 3 Overlap of profile plots to measure pattern similarity. (A) Two overlapping profile plots from a sibling pair with a high degree of pattern similarity (the Southern blot for this pair is shown in Fig. 1, panel A). (B) Two overlapping plots from unrelated patients with full mutation with a low degree of pattern similarity composed of low-intensity overlaps. In each panel solid and dashed lines distinguish separate samples. Females' samples are arbitrarily represented with dashed lines (note the normal allele on the right side of each panel). The area that the plots share in common was used as a measure of similarity and is shaded in gray. The abscissa of each plot corresponds to the baseline, below which area is excluded from analysis. In the panels designated " $1 \times$ background," the baseline is set to the level of the system background. The panels designated " $1.5 \times$ background" and " $2 \times$ background" illustrate the effect on area under the plots when the baseline is set to a level 1.5 and 2 times greater than the system background level, respectively. As the baseline is raised, low intensity overlaps as shown in B fall below the baseline level and are not included in the analysis. In contrast, the coincident peaks in A persist and continue to share area.

Table 1

Full mutation similarity as measured by area in common

\begin{tabular}{lccc}
\hline & \multicolumn{2}{c}{ Mean similarity (\%) } & \\
\cline { 2 - 3 } $\begin{array}{l}\text { Baseline } \\
\text { level }\end{array}$ & $\begin{array}{c}\text { Sibling pairs } \\
(n=16)\end{array}$ & $\begin{array}{c}\text { Unrelated pairs } \\
(n=15)\end{array}$ & $\begin{array}{r}\text { t-Test } P \\
\text { (one-tailed) }\end{array}$ \\
\hline $1 \mathrm{x}$ & 30.0 & 22.4 & .09 \\
$1.5 \mathrm{x}$ & 20.3 & 11.2 & .05 \\
$2 \mathrm{x}$ & 15.2 & 6.2 & .04 \\
$2.5 \mathrm{x}$ & 12.3 & 3.6 & .03 \\
$3 \mathrm{x}$ & 10.0 & 1.5 & .02 \\
\hline
\end{tabular}

structures that are in turn determined by the sequence composition of the repeat and adjacent genomic regions. This possibility is supported by the observation of ordered deletions of CTG repeats in E. coli and the fragile X deletion hotspot as mentioned previously. Support for a potential role of nonrepeated DNA sequence in triplet repeat stability is provided by a study that showed that intergenerational stability of the Machado-Joseph disease CAG repeat is influenced by a C/G polymorphism adjacent to the repeat tract. ${ }^{41}$ Some evidence indicates that familial factors may also influence the inheritance of the Huntington disease (HD) triplet repeat. In a study of juvenile $\mathrm{HD}$, Telenius and colleagues ${ }^{42}$ found a significant correlation between repeat length in sibling pairs. Potential familial influences were further suggested in a study of germ- line mutation at the HD locus, which identified a father and son that shared an unusual mutation spectrum. ${ }^{43}$

Although it is not known whether individuals with fragile $\mathrm{X}$ full mutations inherit a full or premutation, mutation pattern similarity in siblings is more easily accounted for if both siblings inherit the same or similar allele size. In the case of postzygotic expansion, both siblings might inherit the premutation allele size present in the soma and germline of their mother. Prezygotic expansion is more difficult to reconcile and would require either that the premutation to full mutation transition occurs similarly in two or more independent events in the mother's germline or that the expansion occurs in the primordial germ cells, and as a consequence, the same expansion allele is present in multiple oocytes. In either case it is worth noting that the unrelated patients with full mutations used as controls in the pattern overlap strategy were randomly matched without regard to maternal premutation size. Thus, the pattern overlap comparison we made is one between siblings with identical maternal premutation and nonsiblings with random maternal premutation sizes. Although it might have been instructive to pair the nonsiblings according to maternal premutation size, we were unable to do so in this study because of limited maternal information for most of the isolated unrelated full mutation cases. Our results contradict, to a very limited extent, a report that found size mosaicism (coexistence of full and premutation in an individual) does not have a familial basis. ${ }^{44}$ However, because size mosaicism was addressed as a 
binary variable (present or absent), the methodology used was quite different from that of the current study, making comparison of the findings difficult.

In conclusion, our study indicates that patterns of full mutation repeat-length variability are more similar within sibships than in unrelated individuals. This finding suggests that familial factors may influence somatic repeat variation and that careful examination of mutation patterns could provide mechanistically relevant information.

\section{Acknowledgments}

The authors thank Drs. Mitch Turker, Peter Jacky, and Charles Brenner for helpful discussions. We also thank Dr. Bob Wildin for helpful discussions and assistance with data analysis. In addition, we gratefully acknowledge the input of Dr. Will Bloch, who independently analyzed the families presented in this study with a PCR-GeneScan assay. Although the PCR assay did not contribute to the analysis presented here, the GeneScan data provided the impetus for this study by first suggesting the possibility of biologically relevant allele sharing in fragile $\mathrm{X}$ siblings. This study was supported in part by a National Institutes of Health training grant T32 GM08617 (R.W.B.).

\section{References}

1. Kremer EJ, Pritchard M, Lynch M, Yu S, Holman K, Baker E, Warren ST, Schlessinger D, Sutherland GR, Richards RI. Mapping of DNA instability at the fragile X to a trinucleotide repeat sequence (CCG)n. Science 1991;252:1711-1714.

2. Oberle I, Rousseau F, Heitz D, Kretz C, Devys D, Hanauer A, Boue I, Bertheas MF, Mandel JL. Instability of a 550-base pair DNA segment and abnormal methylation in fragile X syndrome. Science 1991;252:1097-1102.

3. Verkerk AJ, Pieretti M, Sutcliffe JS, Fu Y-H, Kuhl DP, Pizzuti A, Reiner O, Richards S, Victoria MF, Zhang FP, Eussen BE, van Ommen G-IB, Blonden LAJ, Riggins GJ, Chastain JL, Kunst CB, Galjaard H, Caskey CT, Nelson DL, Oostra BA, Warren ST. Identification of a gene (FMR-1) containing a CGG repeat coincident with a breakpoint cluster region exhibiting length variation in fragile X syndrome. Cell 1991;65: 905-914.

4. Yu S, Pritchard M, Kremer E. Lynch M, Nancarrow I, Baker E, Holman K, Mulley JC, Warren ST, Schlessinger D, Sutherland GR, Richards RI. Fragile X genotype characterized by an unstable region of DNA. Science 1991;252:1179-1181.

5. Fu YH, Kuhl DP, Pizzuti A, Pieretti M, Sutcliffe JS, Richards S, Verkerk AJ, Holden JJ, Fenwick RG Jr, Warren ST, Oostra BA, Nelson DL, Caskey CT. Variation of the CGG repeat at the fragile $X$ site results in genetic instability: resolution of the Sherman paradox. Cell 1991;67:1047-1058.

6. Heitz D, Rousseau F, Devys D, Saccone S, Abderrahim H, Le Paslier D, Cohen D, Vincent A, Toniolo D, Della Valle G, Johnson S, Schlessinger D, Oberle I, Mandel IL. Isolation of sequences that span the fragile $\mathrm{X}$ and identification of a fragile $\mathrm{X}$-related CpG island. Science 1991;251:1236-1239.

7. Bell MV, Hirst MC, Nakahori Y, Mackinnon RN, Roche A, Flint TI, Jacobs PA, Tommerup N, Tranebjaerg L, Froster-Iskenius U, Kerr B, Turner G, Lindenbaum RH, Winter R, Pembrey M, Thibodeau S, Davies KE. Physical mapping across the fragile $\mathrm{X}$ : hypermethylation and clinical expression of the fragile $\mathrm{X}$ syndrome. $C_{c} l l$ 1991:64:861-866.

8. Vincent A, Heitz D, Petit C, Kretz C, Oberle I, Mandel IL. Abnormal pattern detected in fragile-X patients by pulsed-field gel electrophoresis. Nature 1991;349: 624-626.

9. Sutcliffe JS, Nelson DL, Zhang F, Pieretti M, Caskey CT, Saxe D, Warren ST. DNA methylation represses FMR-1 transcription in fragile $\mathrm{X}$ syndrome. Hum Mol Genet 1992;1:397-400

0. Pieretti M, Zhang FP, Fu YH, Warren ST, Oostra BA, Caskey CT, Nelson DL. Absence of expression of the FMR-1 gene in fragile X syndrome. Cell 1991;66:817-822.

1. Devys D, Lutz Y, Rouyer N, Bellocq JP, Mandel JL. The FMR-1 protein is cytoplasmic, most abundant in neurons and appears normal in carriers of a fragile $X$ pre mutation. Nat Genet 1993;4:335-340.

2. Siomi $H$, Siomi MC, Nussbaum RL, Dreyfuss $G$. The protein product of the fragile $X$ gene, FMR1, has characteristics of an RNA-binding protein. Cell 1993:74:291-298.

3. Snow K, Doud LK, Hagerman R, Pergolizzi RG, Erster SH, Thibodeau SN. Analysis of a CGG sequence at the FMR-1 locus in fragile $X$ families and in the general population. Am J Hum Genet 1993;53:1217-1228.

14. Sutherland GR, Gedeon A, Kornman L, Donnelly A, Byard RW, Mulley IC, Kremer E, Lynch M, Pritchard M, Yu S, Richards RI. Prenatal diagnosis of fragile X syndrome by direct detection of the unstable DNA sequence. N Engl J Med 1991;325: $1720-1722$.

15. Devys D, Biancalana V, Rousseau F, Boue J, Mandel JL, Oberle I. Analysis of full fragile $\mathrm{X}$ mutations in fetal tissues and monozygotic twins indicate that abnormal methylation and somatic heterogeneity are established early in development. Am J Med Genet 1992;43:208-216.

16. Wohrle D, Hirst MC, Kennerknecht I, Davies KE, Steinbach P. Genotype mosaicism in fragile X fetal tissues. Hum Genet 1992;89:114-116.

17. Wohrle D, Hennig I, Vogel W, Steinbach P. Mitotic stability of fragile X mutations in differentiated cells indicates early post-conceptional trinucleotide repeat expansion. Nat G'net 1993;4:140-142.

18. Wohrle D, Kennerknecht I, Woif M, Enders H, Schwemmle S, Steinbach P. Heterogeneity of DM kinase repeat expansion in different fetal tissues and further expansion during cell proliferation in vitro: evidence for a casual involvement of methyldirected DNA mismatch repair in triplet repeat stability. Hum Mol Genet 1995;4: 1147-1153.

19. de Graaff E, Willemsen R, Zhong N, de Die-Smulders CE, Brown WT, Freling G, Oostra $B$. Instability of the CGG repeat and expression of the FMRl protein in a male fragile X patient with a lung tumor. Am J Hum Genet 1995;57:609-618.

20. Moutou C, Vincent MC, Biancalana V, Mandel JL. Transition from premutation to full mutation in fragile X syndrome is likely to be prezygotic. Hum Mol Genet 1997; 6:971-979.

21. Reyniers E, Martin II, Cras P, Van Marck E, Handig I, Jorens HZ, Oostra BA, Kooy RF, Willems PI. Postmortem examination of two fragile $X$ brothers with an FMR 1 full mutation. Am / Med Genet 1999;84:245-249.

22. Tassone F, Hagerman RJ, Gane LW, Taylor AK. Strong similarities of the FMRI mutation in multiple tissues: postmortem studies of a male with a full mutation and a male carrier of a premutation. Am J Med Genet 1999;84:240-244.

23. Kruyer H, Mila M, Glover G, Carbonell P, Ballesta F, Estivill X. Fragile X syndrome and the (CGG)n mutation: two families with discordant MZ twins. Am I Hum Genet $1994 ; 54: 437-442$

24. Antinolo G, Borrego S, Cabeza IC, Sanchez R, Sanchez J, Sanchez B. Reverse mutation in fragile X syndrome. Am J Hum Genet 1996;58:237-239.

25. Burman RW, Popovich BW, Jacky PB, Turker MS. Fully expanded FMR1 CGG repeats exhibit a length-and differentiation-dependent instability in cell hybrids that is independent of DNA methylation. Hum Mol Genct 1999;8:2293-2302.

26. Rousseau F, Robb LJ, Rouillard P, Der Kaloustian VM. No mental retardation in a man with $40 \%$ abnormal methylation at the FMR 1 locus and transmission of sperm cell mutations as premutations. Hum Mol Genet 1994;3:927-930.

27. Nolin SL, Lewis FA III, Ye LL, Houck GE Ir, Glicksman AE, Limprasert P, Li SY, Zhong N, Ashley AE, Feingold E, Sherman SL, Brown WT. Familial transmission of the FMR I CGG repeat. Am I Hum Genet 1996;59:1252-1261.

28. Burman RW, Yates PA, Green LD, Jacky PB, Turker MS, Popovich BW. Hypomethylation of an expanded FMRI allele is not associated with a global DNA methylation defect. Am / Hum Genet 1999;65:1375-1386.

29. Malter HE, Iber IC, Willemsen R, de Graaff E, Tarleton IC, Leisti J, Warren ST Oostra BA. Characterization of the full fragile $\mathrm{X}$ syndrome mutation in fetal gametes. Nat Gent 1997;15:165-169.

30. Mingroni-Netto RC. Haddad LA, Vianna-Morgante AM. The number of CGG repeats of the FMR1 locus in premutated and fully mutated heterozygotes and their offspring: implications for the origin of mosaicism. Am / Med Genct 1996;64:270 273.

31. Richards RI, Sutherland GR. Simple repeat DNA is not replicated simply. Nat Genet 1994:6:114-116

32. McMurray CT. Mechanisms of DNA expansion. Chromosoma 1995;104:2-13.

33. Sinden RR. Biological implications of the DNA structures associated with diseasecausing triplet repeats. Am / Hum Gent 1999;64:346-353.

34. Kang S, laworski A, Ohshima $K$, Wells RD. Expansion and deletion of CTG repeats from human disease genes are determined by the direction of replication in $\mathrm{E}$. coli. Nat Genet 1995:10:213-218.

35. Quan F, Grompe M, Jakobs P, Popovich BW. Spontaneous deletion in the FMRI gene in a patient with fragile $X$ syndrome and cherubism. Hum Mol Genet 1995;4: $1681-1684$.

36. Mila M, Castellvi-Bel S, Sanchez A, Lazaro C, Villa M, Estivill X. Mosaicism for the fragile $X$ syndrome full mutation and deletions within the $C G G$ repeat of the FMR gene. J Med Gine't 1996;33:338-340.

37. Mannermaa A, Pulkkinen L, Kajanoja E, Ryynanen M, Saarikoski S. Deletion in the FMR1 gene in a fragile-X male. Am / Med Ginet 1996;64:293-295.

38. Schmucker B, Ballhausen WG. Pfeiffer RA. Mosaicism of a microdeletion of $486 \mathrm{bp}$ 


\section{Burman et al.}

involving the CGG repeat of the FMRI gene due to misalignment of GTT tandem repeats at chi-like elements flanking both breakpoints and a full mutation. Hum Genet 1996;98:409-414.

39. Hirst MC, White PJ. Cloned human FMRI trinucleotide repeats exhibit a length and orientation-dependent instability suggestive of in vivo lagging strand secondary structure. Nucleic Acids Res 1998;26:2353-2358.

40. Kremer EJ, Yu S, Pritchard M, Nagaraja R, Heitz D, Lynch M, Baker E, Hyland VJ, Little RD, Wada M, Toniolo D, Vincent A, Rousseau F, Schlessinger D, Sutherland $\mathrm{GR}$, Richards RI. Isolation of a human DNA sequence which spans the fragile X. Ain J Hum Genet 1991;49:656-661.

41. Igarashi S, Takiyama Y, Cancel G, Rogaeva EA, Sasaki H, Wakisaka A, Zhou YX Takano H, Endo K, Sanpei K, Oyake M, Tanaka H, Stevanin G, Abbas N, Durr A Rogaev EI, Sherrington R, Tsuda T, Ikeda M, Cassa E, Nishizawa M, Benomar A Julien J, Weissenbach J, Wang GX, Agid Y, St. George-Hyslop PH, Brice A, Tsuji S
Intergenerational instability of the CAG repeat of the gene for Machado-Joseph disease (MIDI) is affected by the genotype of the normal chromosome: implication for the molecular mechanisms of the instability of the CAG repeat. Hum Mol Genet 1996;5:923-932.

42. Telenius H, Kremer HP, Theilmann J, Andrew SE, Almqvist E, Anvret M, Greenberg C, Greenberg J, Lucotte G, Squitieri F, Starr E, Goldberg YP, Hayden MR. Molecular analysis of juvenile Huntington disease: the major influence on (CAG)n repeat length is the sex of the affected parent. Hum Mol Genet 1993;2:1535-1540.

43. Leeflang EP, Tavare S, Marjoram P, Neal CO, Srinidhi J, MacFarlane H, MacDonald ME, Gusella JF, de Young M. Wexler NS, Arnheim N. Analysis of germline mutation spectra at the Huntington's disease locus supports a mitotic mutation mechanism. Hum Mol Genet 1999;8:173-183.

44. Nolin SL, Glicksman A, Houck GE Jr, Brown WT, Dobkin CS. Mosaicism in fragile $X$ affected males. Am J Med Genet 1994;51:509-512. 